
\title{
$\begin{array}{ll}\text { Research Square } & \begin{array}{l}\text { Preprints are preliminary reports that have not undergone peer review. } \\ \text { They should not be considered conclusive, used to inform clinical practice, } \\ \text { or referenced by the media as validated information. }\end{array}\end{array}$
}

\section{Supplementing Substance Use Prevention with Sexual Health Education A Partner-Informed Approach to Intervention Development}

Terrinieka W Powell ( $\nabla$ terri.powell@jhu.edu )

Johns Hopkins University Bloomberg School of Public Health https://orcid.org/0000-0003-3254-059X

Meghan Jo

Johns Hopkins University Bloomberg School of Public Health

Anne D. Smith

Johns Hopkins University Bloomberg School of Public Health

Beth D. Marshall

Johns Hopkins University Bloomberg School of Public Health

Santha Thigpen

Maree G. Farring Elementary Middle School

Asari Offiong

Johns Hopkins University Bloomberg School of Public Health

Sophia R. Geffen

Johns Hopkins University Bloomberg School of Public Health

\section{Research article}

Keywords: adolescent, sex education, methods, prevention

Posted Date: March 2nd, 2020

DOI: https://doi.org/10.21203/rs.3.rs-15644/v1

License: (1) This work is licensed under a Creative Commons Attribution 4.0 International License. Read Full License

Version of Record: A version of this preprint was published at Health Promotion Practice on August 5th, 2020. See the published version at https://doi.org/10.1177/1524839920947683. 


\section{Abstract}

Background Threats to adolescent health have been shown to co-occur and influence one another. Supplementing substance use prevention with sexual health education would allow educators to address the risk and protective factors that influence both health issues. This streamlined approach may minimize the inefficiencies of multi-session, single-purpose interventions.

Methods LifeSkills Training (LST) for middle school is a skills-based cognitive behavioral prevention program delivered over three years during grades 6-8, with a focus on substance use and violence prevention. This paper describes the development of a supplemental sexual and reproductive health (SRH) unit for the middle school LST curriculum, in partnership with content experts and school personnel. This partnerinformed approach took place across three key phases: 1) formative insights, 2) unit development, and 3) pilot implementation.

Result The final supplemental SRH unit is ten 45 -minute sessions offered to 7 th and 8 th grade students and includes a set of learning objectives that are aligned with individual sessions. The supplemental SRH unit also mirrors existing LST modules in length, flow, layout, facilitator instructions, focus on prevention, and utilization of a student workbook.

Conclusions Our findings suggest that there is great potential in partnering with content experts and school personnel to develop supplemental materials for existing interventions. This collaborative approach resulted in a set of sessions that are medically accurate and developmentally appropriate. This partnership approach may serve as a model for future researchers and practitioners aiming to extend the reach of existing evidence-based programs.

\section{Background}

Adolescence is a sensitive period in the life course, during which increased sensation-seeking driven by neuro-cognitive development leaves young people more likely to engage in high-risk and potentially harmful behaviors including binge drinking, illicit substance use, unprotected sex, and violence [1]. Teens' increased propensity for risk behaviors during this period holds significant implications for their health and wellbeing-in 2017 alone, 74\% of adolescent deaths in the United States were due to causes that were behavioral in origin, the vast majority of which were unintentional injuries, followed by homicides and suicides) [2]. In addition to mortality risk, behaviors developed during adolescence have the potential to impact long-term health and wellbeing through, for example, early unplanned childbearing, and chronic illnesses associated with sustained tobacco smoking or alcohol use [3].

These threats to long-term health are exacerbated by the fact that adolescent risk behaviors have been shown to both co-occur and influence one another [4]. Adolescent substance use has been associated with earlier age of first sex, increased risk of unprotected sex, and a higher number of sexual partners $[5,6]$. In turn, substance use is associated with increased perpetration of violence, including violence against dating partners in adolescence $[7,8]$. The interrelationship between different adolescent risk behaviors, such as substance use and sexual risk-taking, is further supported by their shared risk and protective factors. Early exposure to adverse childhood experiences or maltreatment, including physical or sexual abuse, growing up in a low-income neighborhood, and engaging with peers who practice deviant or violent behavior have been linked with increased propensity for violence, substance use or misuse, and sexual risk-taking in adolescence [9-12]. At the same time, school connection, parental attachment, and neighborhood collective efficacy are linked with decreased propensity for substance use and sexual risk taking [13-15].

Researchers and practitioners have developed a growing number of evidence-based interventions that have proven to be effective in preventing or reducing specific targeted health risk behaviors, including tobacco and substance use, violence and aggression and unsafe sexual behaviors [16-18]. School-based programs in particular have been shown to positively impact multiple health risk factors and academic outcomes [19]. However, schools may lack the capacity to implement different multi-session, single-purpose interventions to address individual health risk behaviors, presenting a key gap between intervention developers and implementers. This is especially inefficient given the cooccurrence of adolescent health risk behaviors and their shared underlying causes and protective factors.

\section{Lifeskills Training (LST)}

LifeSkills Training (LST) for middle school is a skills-based cognitive behavioral prevention program delivered over three years during grades 6-8 that focuses on building competence in three domains-personal self-management, social competence, and risk behavior resistance. LST combines subject-specific knowledge related to particular risk behaviors with foundational skills-building in line with positive youth development approaches that target youth asset-building as a risk prevention approach [20]. Originally developed as a tobacco prevention curriculum and later expanded to include other substance use and youth violence prevention, LST has been widely implemented in diverse contexts, and has been shown to reduce the risks of alcohol, tobacco, drug abuse and violence among middle school students [21, 22]. 
However, to date LST has not included a focus on sexual and reproductive health (SRH), which may be a missed opportunity to expand the reach and impact of this curriculum.

\section{A Partnership Approach To Intervention Development}

In 2014, a university partner, school district and city health department partnered to address the high rates of substance use, interpersonal violence, and sexual risk-taking experienced among middle school-aged students across the city. Many of the city's young residents experience considerable risks and have limited access to factors that promote positive youth development $[23,24]$. Compared to the nation, the city has a higher percentage of children living below the poverty line (32\% vs. 18\%) [25]. Over one half of the city's high school students have had at least one drink of alcohol and nearly one half have used marijuana at least once [26]. Teen birth rate in the city is over two times the state average and 1.5 times the national average $[25,27]$. Middle school students in the city are at uniquely high risk of negative sexual health outcomes. An estimated $13 \%$ of middle school students in the city have engaged in sexual intercourse, compared to $6.8 \%$ in the state of Maryland [28].

The city has a history of implementing LST in middle schools, primarily among high-risk 6th graders. The goal of this partnership was to expand risk prevention efforts through the addition of a specific sexual health unit to the LST curriculum, and the implementation of LST in middle school classrooms across grades 6-8. This paper describes the process of developing a supplemental sexual health unit for the LST curriculum.

\section{Methods}

The development of a supplemental sexual and reproductive health unit (hereafter referred to as supplemental SRH unit) was led by the university partner. The university partner is a CDC-funded, Prevention Research Center that assists urban youth in becoming healthy and productive adults. Together with its community partners, the university partner conducts research that identifies the needs and strengths of young people and tests programs designed to promote their health and well-being. Accordingly, the university partner took on a partnerinformed approach to developing a supplemental sexual health unit for LST. A partner-informed approach ensured that all content was informed by both researchers and practitioners. This process took place across three key phases: 1) formative insights, 2) unit development, and 3) pilot implementation.

The first formative phase involved consultations with SRH educational research experts, school administrators, and local and state standards to identify target goals of the unit and corresponding content. The second phase involved unit creation by a team of faculty, researchers, and graduate students at the university partner in collaboration with a current middle school teacher. The third and final phase involved pilot implementation of the prototype unit in four pubic middle schools, and iterative refinement of the unit sessions based on implementer feedback. This phase also involved consultation with a gender and sexuality expert to enhance the inclusivity of the unit content. All research was approved by the institutional review board. Each phase is described in detail below.

\section{Phase 1: Formative Insights}

Recognizing the multiple competing priorities of public school administrators and educators, the university partner began by conducting key informant interviews with principals at five partner middle schools to better understand the factors important for successful implementation of a classroom-based risk prevention curriculum. Topics covered included needs of the student population, barriers and opportunities to program implementation, decision-making processes in selecting programs, and past experiences implementing programs. Principals expressed desire for comprehensive and ongoing teacher training, including a "complete package" of a curriculum and supplemental training materials. In addition, while all principals acknowledged significant need for a risk behavior prevention curriculum, they also highlighted the time constraints of teachers, and the need for flexibility in unit length and design. Principals noted that sexual health topics were addressed differently across schools. Some schools invited outside programs to address the issues (e.g., Planned Parenthood or medical students from local hospital). Others introduced a limited number of topics through their science courses when appropriate. This information was later used to inform successful unit development and implementation.

In parallel with principal interviews, the university partner conducted a review of the existing health standards used by the school district including the Maryland State Voluntary Curriculum, the city's Health Curriculum Scope and Sequence and the National Health Education Standards. The lesson content of three other evidence-based teen pregnancy prevention curricula were also reviewed to better understand the common components of those programs, their overlap with existing LST curriculum and Maryland standards, and common strategies that may be adapted for the supplemental SRH unit. The following curricula were reviewed: It's Your Game: Keep It Real, Draw the Line/Respect the Line, and Making Proud Choices! Out Of Home Care [29-31]. Information from these curricula, combined with city data conveying earlier sexual initiation and higher pregnancy and STI rates among adolescents compared to state and national averages, led the team to focus on

Page 3/9 
two key behavioral outcomes for the supplemental SRH unit: (1) delaying sexual initiation and (2) increasing protective behaviors among students when they become sexually active.

\section{Phase 2: Unit Development}

The original development of the LST curriculum was informed by social learning theory and problem behavior theory [32-34]. Social learning theory posits that behaviors are learned in the context of a social environment through the process of observation, imitation, and modeling. Behaviors are motivated by social influencers, including peers and role models, as well as individual factors, including knowledge, cognition, attitudes, and expectations [32,33]. Problem behavior theory involves the application of social learning theory to adolescent "problem" or risk behaviors [34]. We extended these theoretical groundings to the development of the supplementary SRH unit. In addition, we applied a positive youth development approach, which harnesses young peoples' existing competencies and resources by further equipping them with relevant skills and information, rather than attempting to overcome deficits through behavioral corrections [35].

To develop learning objectives tied to our intended behavioral outcomes of delayed sexual initiation and increased protective behaviors, the university partner held a two-day working meeting facilitated by a youth sexual and reproductive behavior change expert. The workshop was attended by faculty, staff, and graduate research assistants from the university. Based on achieving a balance of classroom time and SRH content, the team determined that the supplemental SRH unit would be a minimum of eight 45-minute sessions offered to 7th and 8th grade students. Based on this guidance, the team developed a set of learning objectives for the supplemental SRH unit and aligned them with individual sessions, ensuring that all learning objectives were met over the course of LST implementation.

Sessions were collaboratively written by the research team and the participating middle school teacher. The following common core components of adolescent pregnancy prevention programs were incorporated: 1) Clear health goals; 2) A focus on specific reproductive health behaviors; 3) An emphasis on multiple psychosocial protective factors affecting sexual behaviors (e.g., knowledge, perceived risks, values, attitudes, perceived norms, and self-efficacy) [36]. The team developed a set of corresponding activities for each objective in partnership with stakeholders and consultants. In line with social learning theory, behavioral modeling and rehearsal were commonly incorporated into activities. Finally, the team sought to ensure that the curriculum was inclusive of diverse genders and sexual orientations. Schools that teach LGBTQ-inclusive sex education have been shown to have lower odds of LGBTQ students reporting being bullied in school and experiencing adverse mental health outcomes [37].

The supplemental SRH unit was developed to seamlessly fit with the LST program. Specifically, the supplemental SRH unit aligns with LST in length and flow of lessons, layout of content, written instructions for facilitators, focus on prevention, and utilization of a student workbook alongside sessions. In addition, teaching strategies used in LST, including facilitation, coaching, behavioral rehearsal and assessment, were extended to the supplemental SRH unit. Similarly, the supplemental SRH unit was designed to build on objectives and skills introduced and practiced in LST class sessions-such as decision-making, communication, and assertiveness-by reinforcing them and applying them to another domain of health. In total, eight sessions comprising the initial supplemental SRH unit were developed.

\section{Phase 3: Pilot Test}

The university partnered with two public middle schools to pilot the implementation of the supplemental SRH unit among 7th and 8th grade students during the academic year. All sessions were delivered during science class by a teacher or school counselor. Based on insights collected from principals during Phase 1, the university partner prioritized three areas to ensure successful pilot implementation:

comprehensive training, school-specific scheduling, and ongoing support. To ensure facilitators received comprehensive training, the university team provided trainings at accessible times and locations and allowed teacher-facilitators to practice with their peers before implementing with students. Each school required school-specific scheduling which meant the time of year and weekly frequency of implementation varied across schools. Finally, the university partner agreed to quickly respond to requests for classroom support, additional materials (e.g., post its, flip charts, markers and funding for student activities (e.g., end of unit pizza parties) to show their ongoing support of the school and program.

Prior to conducting the pilot test, all school personnel who would be implementing the supplemental SRH unit-all of whom were teachersattended a half-day training developed by a team member from the university. During the training, the trainer explained key elements of a sex positive teaching approach and how the supplemental SRH unit aligned with the existing LST program. Teachers shared their previous experiences and their concerns about leading discussions around SRH with students. They practiced strategies for teaching content related to adolescent SRH and discussed the content of each session. Time was allotted for practice leading the sessions, answering questions and providing a set of local and national resources, including online and print materials that offer additional information about sexual health topics covered in the supplemental SRH unit. It was crucial for implementers to feel both comfortable and competent that they could deliver it as designed and evaluations from the training showed this to be the case.

Page $4 / 9$ 
Because the supplemental SRH sessions were designed to both build upon one another and the LST program, the pilot test was conducted over a period of two years with one cohort of students receiving LST and the supplemental unit in two public middle schools. The 7th grade sessions were delivered in the first year and the 8th grade sessions were delivered in the second year. Each session was observed by a member of the research team using a standardized observation form. Facilitators also provided feedback for each session using an electronic fidelity log that asked a set of standard questions about the delivery of each session (e.g., student engagement and modifications made). The pilot test period allowed the university team to iteratively improve the unit and resources based on feedback from facilitators, who had a range of prior experience teaching sexual health education. For example, prior to year two of the pilot test, modifications were made to the 8th grade sessions based on 7th grade teacher-facilitator feedback.

At the end of the two-year pilot test with both 7th and 8th grade students, the university team revised the supplemental SRH unit based on feedback obtained from teacher fidelity logs and in-person observations. In addition to the observation notes, and fidelity logs, the research team solicited feedback on implementation through one on one meetings with individual facilitators. Facilitators provided feedback on the following topics: flow of the SRH unit, student responses, challenges and future considerations. Additionally, the university partnered with the national Gay, Lesbian Sexuality Education Network (GLSEN) to ensure inclusivity and that proper terminology was being used throughout the supplemental SRH unit. Table 1 lists examples of the types of feedback received and addressed in the final version of the supplemental SRH unit.

Table 1

Examples of Partner Feedback

\begin{tabular}{|c|c|c|}
\hline Source & Feedback & Modifications Made \\
\hline \multirow[t]{3}{*}{ Facilitators } & Lack of knowledge among students of puberty & $\begin{array}{l}\text { Additional resources offered to facilitators; additional puberty } \\
\text { session developed }\end{array}$ \\
\hline & $\begin{array}{l}\text { Student confusion around gender-neutral names } \\
\text { and relationships }\end{array}$ & $\begin{array}{l}\text { Fewer gender-neutral names; range of relationships presented } \\
\text { throughout unit }\end{array}$ \\
\hline & Media influences on sexual behaviors felt redundant & $\begin{array}{l}\text { Session on sexual influences in the media removed; media } \\
\text { influences mentioned when appropriate throughout unit }\end{array}$ \\
\hline \multirow[t]{3}{*}{$\begin{array}{l}\text { GLSEN } \\
\text { Partner }\end{array}$} & $\begin{array}{l}\text { Unit limited in terminology used to describe gender, } \\
\text { sexual identity and sexual orientation }\end{array}$ & $\begin{array}{l}\text { Broader range of terms incorporated; list of terms and reference in } \\
\text { unit created for facilitators }\end{array}$ \\
\hline & $\begin{array}{l}\text { Statistics primarily for heterosexual, cisgender } \\
\text { students }\end{array}$ & Statistics for LGBTQ students included when available \\
\hline & Some definitions reinforce gender binary & $\begin{array}{l}\text { Revision of definitions to ensure that agender, nonbinary, intersex } \\
\text { and gender queer people are included }\end{array}$ \\
\hline
\end{tabular}

\section{Results}

The final supplemental SRH unit had 10 sessions; five sessions that could be delivered in 7th grade and five sessions in 8th grade. Sessions were confined to 45 minutes to be consistent with both the original LST curriculum and responsive to teacher schedules. Two sessions were allotted for topics that required more than 45 minutes. Throughout the unit, students are able to demonstrate their understanding through a range of activities facilitated during class and described in a corresponding student guide. Table 2 lists the final titles and objectives for each session. 
Table 2

Session Titles and Goals of Final Supplemental SRH Unit

\begin{tabular}{|c|c|c|}
\hline & Session Title & Objectives \\
\hline \multirow[t]{4}{*}{$\begin{array}{l}\text { 7th Grade } \\
\text { Sessions }\end{array}$} & Puberty (Optional) & $\begin{array}{l}\text { - Identify the parts of the female and male reproductive system } \\
\text { - Describe the functions of the female and male reproductive systems } \\
\text { - Identify the changes that take place during puberty } \\
\text { - Describe the phases of the menstrual cycle } \\
\text { - Develop skills to manage the physical, emotional and social changes of puberty }\end{array}$ \\
\hline & $\begin{array}{l}\text { Sexual Health: Myths and } \\
\text { Realities }\end{array}$ & $\begin{array}{l}\text { - Define the difference between assigned sex and gender identity } \\
\text { - Identify that most teenagers are not sexually active } \\
\text { - Identify reasons why adolescents engage and do not engage in sexual activity } \\
\text { - Define abstinence }\end{array}$ \\
\hline & $\begin{array}{l}\text { Boundaries } \\
(2 \text { sessions })\end{array}$ & $\begin{array}{l}\text { - Clarify their personal boundaries around sex } \\
\text { - Identify how to protect their boundaries } \\
\text { - Practice resisting persuasion in relation to offers of sexual activity } \\
\text { - Practice techniques for dealing with direct pressure to engage in activities that challenge } \\
\text { their personal boundaries }\end{array}$ \\
\hline & Risks & $\begin{array}{l}\text { - Review sexual transmitted infections } \\
\text { - Identify symptoms and effects on the body of STIs } \\
\text { - Discuss prevention of STIs }\end{array}$ \\
\hline \multirow[t]{5}{*}{$\begin{array}{l}\text { 8th Grade } \\
\text { Sessions }\end{array}$} & $\begin{array}{l}\text { Sexual and Reproductive } \\
\text { Health: Myths and Realities }\end{array}$ & $\begin{array}{l}\text { - Review the basics of sexual and reproductive health } \\
\text { - Analyze media portrayals of sex } \\
\text { - Identify that most middle school students are not having sex and that most parents and } \\
\text { caregivers think it is important for young people to wait to have sex } \\
\text { - Understand the prevalence of pregnancy among teens }\end{array}$ \\
\hline & Boundary Setting & $\begin{array}{l}\text { - Identify their personal boundary around sex } \\
\text { - Identify sexual situations that may be risky and identify alternatives } \\
\text { - Practice techniques for dealing with pressure to engage in sexual activity }\end{array}$ \\
\hline & Relationships & $\begin{array}{l}\text { - Identify behaviors that contribute to healthy and unhealthy dating relationships } \\
\text { - Create a definition for a healthy dating relationship } \\
\text { - Discuss responsibilities of being in a dating relationship }\end{array}$ \\
\hline & Identifying Risks & $\begin{array}{l}\text { - Identify risks that come with sexual activity } \\
\text { - Distinguish between high and low risk sexual behaviors } \\
\text { - Identify actions that protect against pregnancy and STIs }\end{array}$ \\
\hline & Reducing Risks & $\begin{array}{l}\text { - Learn about the benefits of clinical care and their rights to access sexual and reproductive } \\
\text { health care } \\
\text { - Learn how to use a condom }\end{array}$ \\
\hline
\end{tabular}

The 7th grade sessions introduce students to the topics of sexual and reproductive health, accurate terminology, boundary setting, and protective and risky behaviors. Not all students receive health education in elementary school. Therefore, there seemed to be little consensus on the basic set of knowledge among middle school students. As a result, implementing the supplemental SRH unit with 7th grade students proved to be challenging. As a result, there is an optional session at the start of the unit, which reviews puberty, available for facilitators whose students need it. Session 1 includes a transition to bridge the LST program to the new modules and invites students to examine statistics and think about reasons young people their age may or may not be engaging in sex. In the first session, an anonymous question box is introduced. The anonymous question box allows students to ask questions that they might not feel comfortable asking in front of their peers due to fear of embarrassment or fear of exposing their behaviors or identities. For example, an LGBTQ student might have a question about behaviors or resources specific to their sexual orientation or gender identity which they may not feel comfortable asking if they are not out to their classmates. Session 2 and 3 are combined and provide a scaffolded approach for students to apply the boundary setting skills and decisionmaking model developed in prior LST sessions to sexual health with a new focus on consent. During session 4 students learn about the potential consequences of unsafe sexual behavior, specifically information related to sexually transmitted infections.

The five 8th grade sessions follow a similar pattern, first providing an overview of sexual and reproductive health, then examining boundaries. These sessions serve as reinforcement of the sessions in 7th grade and focus more heavily on the application of skills than the 7th grade sessions. They have a specific focus on relationships, then skill building around identifying and reducing risks. Session 1 provides a review of sexual and reproductive health and puberty, challenges students to analyze media portrayals of sex, discusses teen pregnancy and again serves as a bridge between the LST program and the SRH unit. In session 2, students are given the chance to reevaluate and update their personal boundaries around sex, in addition to identifying risk situations, and practicing techniques when they are pressured to engage in an activity that goes against their personal boundary. Characteristics and responsibilities within relationships, including dating relationships, are the main topic in Session 3. Finally, sessions 4 and 5 concentrate on the risks associated with sexual activity. Behaviors, including 
masturbation and vaginal sex are discussed. Actions to protect against pregnancy and STIs are also discussed; students are also challenged to identify the benefits of clinic care to sexual health and learn about the use of condoms as a barrier method.

\section{Discussion}

Existing evidence-based interventions may be too costly or narrowly focused for some schools to implement. Moreover, adaptations that are not informed by knowledgeable stakeholders may not meet the needs of schools. There is great potential in taking a partnership approach to developing supplemental materials for existing interventions. The development of this supplemental SRH unit was informed by existing theories, content experts and most importantly school personnel. By relying on a rigorous research plan, knowledgeable partners, and an intense piloting process, this collaborative approach has resulted in a set of inclusive sessions that incorporate medically accurate and developmentally appropriate middle school content that aligns with NHES. This partnership approach may serve as a model for future researchers and practitioners aiming to extend the reach of existing evidence-based programs.

The strengths of this process are rooted in its ability to apply a multi-disciplinary, collaborative approach to developing a sexual and reproductive health module for urban middle school students. Partnering with content experts and school personnel allowed the university partner to develop a supplemental SRH unit that aligned with both National Health Education Standards and the current needs of the school settings. Involvement from teachers in the initial development phases helped the team easily translate complex topics into middle school reading levels and social context. Feedback from teachers also allowed the team to consider and include additional resources to prepare facilitators with responses to commonly asked questions about SRH topics.

This approach was not without challenges. First, administration and teacher turnover were common. Having a clear onboarding packet was key to ensuring that the partnerships with schools would continue regardless of personnel changes. Our onboarding packet included a description of the overall project, the role of each stakeholder, a list of project and school contacts, and a FAQ sheet.

Despite these challenges, our team learned that there was both interest and need for more integrated interventions that address the common risky behaviors experienced by adolescents. School personnel were committed to helping youth grow; this flexible and easy-to-teach integrated intervention allowed facilitators to address a range of risk-taking behaviors in a systematic way across time. Furthermore, we learned the value of thoughtfully using inclusive language throughout the supplemental SRH unit. It became evident that surface level inclusion efforts (e.g. gender-neutral names) were insufficient in properly representing the diverse experiences of young people. We proactively challenged heteronormative norms and attempted to integrate language, characters and tips to support both facilitators and students. The involvement of GLSEN, an expert in this area, helped to ensure that the supplemental SRH unit was both contemporary, appropriate and respectful.

\section{Conclusions}

The collaboration that went into the development of this supplemental SRH unit has resulted in sessions that easily align with an existing evidence-based intervention and is responsive to stakeholder feedback. This study is ongoing; field testing of the final supplemental SRH unit is currently being implemented in two schools. This includes pre- and post-test assessments from students, fidelity assessments from facilitators, as well as an analysis of school and community level trends. We must await the findings from the evaluation research to know if the supplemental SRH unit has the intended preventative effect on adolescent sexual risk taking.

\section{Abbreviations}

\begin{tabular}{ll} 
FAQ & Frequently Asked Questions \\
\hline GLSEN & Gay, Lesbian and Straight Edcuation Network \\
\hline LGBTQ & Lesbian, Gay, Bisexual, Transgenderd and Queer \\
\hline LST & LifeSkills Training \\
\hline NHES & National Health Education Standards \\
\hline SRH & Sexual and Reproductive Health \\
\hline STI & Sexually Transmitted Infection
\end{tabular}

\section{Declarations}

\section{Ethics approval and consent to participate}


This research was approved by the Institutional Review Board at the Johns Hopkins Bloomberg School of Public Health and the Baltimore City Public School System (IRB \#6902 and 0321, respectively). Verbal consent was obtained from all participants.

\section{Consent for publication}

Not applicable

\section{Availability of data and materials}

Not applicable

Competing interests

The authors declare that they have no competing interests.

\section{Funding}

The development of the supplemental sexual health unit was financially supported by the Cooperative Agreement (Number 1-U48-DP-000040) funded by the Centers for Disease Control and Prevention, Prevention Research Center Program. Its contents are solely the responsibility of the authors and do not necessarily represent the official views of the Centers for Disease Control and prevention or the Department of Health and Human Services. TWP was also financially supported by the National Institute on Drug Abuse (1K01DA042134-01A1) to develop this manuscript. The funders did not play a role in the design, conduct or analysis of the study nor in the drafting of this manuscript.

\section{Authors' contributions}

TWP, MJ, BDM, and ST were involved in the development of the supplemental modules. TWP, MJ and ADS drafted the manuscript. All authors read and revised draft versions of the manuscript and approved the final manuscript.

\section{Acknowledgements}

We would like to thank Baltimore City Public School System and the schools who participated in this research.

\section{References}

1. Steinberg L. A social neuroscience perspective on adolescent risk-taking. Developmental review. 2008;28(1):78-106.

2. Heron MP. Deaths: Leading causes for 2017. . 2019.

3. Sawyer SM, Afifi RA, Bearinger LH, Blakemore S, Dick B, Ezeh AC, et al. Adolescence: a foundation for future health. The Lancet. 2012;379(9826):1630-40.

4. de Winter AF, Visser L, Verhulst FC, Vollebergh WA, Reijneveld SA. Longitudinal patterns and predictors of multiple health risk behaviors among adolescents: The TRAILS study. Prev Med. 2016;84:76-82.

5. Ritchwood TD, Ford H, DeCoster J, Lochman JE, Sutton M. Risky sexual behavior and substance use among adolescents: A meta-analysis. Children and Youth Services Review. 2015;52:74-88.

6. Tucker JS, Ryan GW, Golinelli D, Ewing B, Wenzel SL, Kennedy DP, et al. Substance use and other risk factors for unprotected sex: Results from an event-based study of homeless youth. AIDS and Behavior. 2012;16(6):1699-707.

7. Ellickson PL, McGuigan KA. Early predictors of adolescent violence. Am J Public Health. 2000 Apr;90(4):566-72.

8. Temple JR, Shorey RC, Fite P, Stuart GL, Le VD. Substance use as a longitudinal predictor of the perpetration of teen dating violence. Journal of youth and adolescence. 2013;42(4):596-606.

9. Hussey JM, Chang JJ, Kotch JB. Child maltreatment in the United States: prevalence, risk factors, and adolescent health consequences. Pediatrics. 2006 Sep;118(3):933-42.

10. Thibodeau M, Lavoie F, Hébert M, Blais M. Childhood maltreatment and adolescent sexual risk behaviors: Unique, cumulative and interactive effects. Child Abuse Negl. 2017;72:411-20.

11. Haynie DL, Silver E, Teasdale B. Neighborhood characteristics, peer networks, and adolescent violence. Journal of Quantitative Criminology. 2006;22(2):147-69.

12. Cubbin C, Santelli J, Brindis CD, Braveman P. Neighborhood context and sexual behaviors among adolescents: Findings from the National Longitudinal Study of Adolescent Health. Perspectives on sexual and reproductive health. 2005;37(3):125-34. 
13. Resnick MD, Bearman PS, Blum RW, Bauman KE, Harris KM, Jones J, et al. Protecting adolescents from harm: findings from the National Longitudinal Study on Adolescent Health. JAMA. 1997;278(10):823-32.

14. Browning CR, Leventhal T, Brooks-Gunn J. Neighborhood context and racial differences in early adolescent sexual activity. Demography. 2004;41(4):697-720.

15. Fagan AA, Wright EM, Pinchevsky GM. The protective effects of neighborhood collective efficacy on adolescent substance use and violence following exposure to violence. Journal of youth and adolescence. 2014;43(9):1498-512.

16. Soole DW, Mazerolle L, Rombouts S. School-based drug prevention programs: A review of what works. Australian \& New Zealand Journal of Criminology. 2008;41(2):259-86.

17. Mytton JA, DiGuiseppi C, Gough DA, Taylor RS, Logan S. School-based violence prevention programs: systematic review of secondary prevention trials. Arch Pediatr Adolesc Med. 2002;156(8):752-62.

18. Kirby D, Laris BA. Effective curriculum-based sex and STD/HIV education programs for adolescents. Child Development Perspectives. 2009;3(1):21-9.

19. Flay BR. Positive youth development requires comprehensive health promotion programs. Am J Health Behav. 2002;26(6):407-24.

20. Botvin GJ, Griffin KW. Life skills training: preventing substance misuse by enhancing individual and social competence. New directions for youth development. 2014;2014(141):57-65.

21. Botvin GJ, Griffin KW, Nichols TD. Preventing youth violence and delinquency through a universal school-based prevention approach. Prevention science. 2006;7(4):403-8.

22. Botvin GJ, Kantor LW. Preventing alcohol and tobacco use through life skills training. Alcohol Research and Health. 2000;24(4):250-7.

23. Leaf, PJ, Ahmed S-R, Bettencourt A, Connelly F, Furr-Holden D, Milan A, Pate C, Soleimanpour S, Abrahams M. Health and well-being of Baltimore's Children, youth and Families: Opportunities and Challenges. 2013.

24. Marshall BD, Astone N, Blum RW, Jejeebhoy S, Delany-Moretlwe S, Brahmbhatt H, et al. Social capital and vulnerable urban youth in five global cities. Journal of Adolescent Health. 2014;55(6):S21-30.

25. KIDS COUNT Data Center [Internet]. [cited 5/9 2019]. Available from: https://datacenter.kidscount.org.

26. 2016 YRBS Baltimore City High School Summaries [Internet].; 2018 [cited 5/9 2019]. Available from: https://phpa.health.maryland.gov/ccdpc/Reports/Documents/2016\%20YRBS\%20YTS\%20Reports/MDH\%20YRBS_Report_2016_final.pdf.

27. Maryland Vital Statistics Annual Report 2017 [Internet].; 2018 [cited 5/10/2019 2019]. Available from: https://health.maryland.gov/vsa/Documents/Reports\%20and\%20Data/Annual\%20Reports/2017annual_revised.pdf.

28. 2016 YRBS Baltimore Middle School Summaries [Internet].; 2018 [cited 5/9 2019]. Available from: https://phpa.health.maryland.gov/ccdpc/Reports/Pages/YRBS2016.aspx.

29. Tortolero SR, Markham CM, Peskin MF, Shegog R, Addy RC, Escobar-Chaves SL, et al. It's Your Game: Keep It Real: delaying sexual behavior with an effective middle school program. Journal of Adolescent Health. 2010;46(2):169-79.

30. Coyle KK, Kirby DB, Marín BV, Gómez CA, Gregorich SE. Draw the line/respect the line: A randomized trial of a middle school intervention to reduce sexual risk behaviors. Am J Public Health. 2004;94(5):843-51.

31. Jemmott III JB, Jemmott LS, Fong GT. Abstinence and safer sex HIV risk-reduction interventions for African American adolescents: a randomized controlled trial. JAMA. 1998;279(19):1529-36.

32. Botvin GJ, Baker E, Renick NL, Filazzola AD, Botvin EM. A cognitive-behavioral approach to substance abuse prevention. Addict Behav. 1984;9(2):137-47.

33. Bandura A. Social learning theory of aggression. J Commun. 1978;28(3):12-29.

34. Jessor R. Problem behavior and developmental transition in adolescence. J Sch Health. 1982;52(5):295-300.

35. Damon W. What is positive youth development? Ann Am Acad Pol Soc Sci. 2004;591(1):13-24.

36. Kirby D, Laris BA, Rolleri L. Impact of sex and HIV education programs on sexual behaviors of youth in developing and developed countries. Family Health International, YouthNet Program Durham, NC; 2005.

37. Proulx CN, Coulter RW, Egan JE, Matthews DD, Mair C. Associations of Lesbian, Gay, Bisexual, Transgender, and Questioning-Inclusive Sex Education With Mental Health Outcomes and School-Based Victimization in US High School Students. Journal of Adolescent Health. 2019;64(5):608-14. 